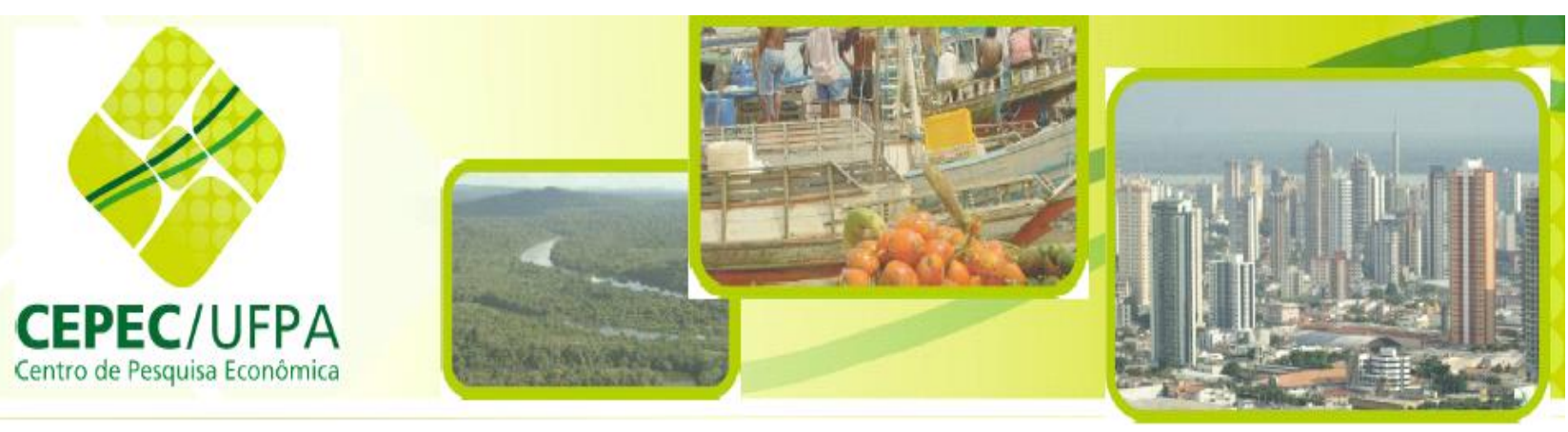

ISSN 2238-118X

\title{
CADERNOS CEPEC
}

V. 2 N. 5 Maio de 2013

O comércio exterior brasileiro e a questão regional: elementos da dinâmica econômica do estado do Pará nas duas últimas décadas

Nathalya Rocha

José Raimundo B. Trindade

Centro de Pesquisas Econômicas da Amazônia

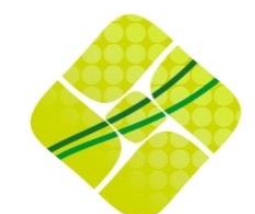

CEPEC/UFPA 


\section{CADERNOS CEPEC}

Publicação do Programa de Pós-graduação em Economia da Universidade Federal do Pará

Periodicidade Mensal - Volume 2-N 5 - Maio de 2013

Reitor: Carlos Edilson de Oliveira Maneschy

Vice Reitor: Horácio Shneider

Pró-Reitor de Pesquisa e Pós Graduação: Emmanuel Zagury Tourinho

Instituto de Ciências Sociais Aplicadas

Diretor: Marcelo Bentes Diniz

Vice Diretora: Maria José de Souza Barbosa

Coordenador do Mestrado em Economia: Sérgio Rivero

Editores

José Raimundo Barreto Trindade

Sérgio Rivero

Conselho Editorial

$\begin{array}{lll}\text { Armando Souza } & \text { Francisco Costa } & \text { Gilberto Marques } \\ \text { Marcelo Diniz } & \text { José Nilo } & \text { Sérgio Rivero } \\ \text { David Carvalho } & \text { José Trindade } & \text { Gisalda Filgueiras } \\ \text { Raimundo Cota } & \text { Danilo Fernandes } & \end{array}$

Comentários e Submissão de artigos devem ser encaminhados ao Centro de Pesquisas Econômicas da Amazônia, através do e-mail: jrtrindade@uol.com.br

Página na Internet: http://www.ppgeconomia.ufpa.br/ 


\section{Cadernos CEPEC}

\section{Missão e Política Editorial}

Os Cadernos CEPEC constituem periódico mensal vinculado ao Programa de Pós-graduação em Economia do Instituto de Ciências Sociais Aplicadas (ICSA) da Universidade Federal do Pará (UFPA). Sua missão precípua constitui no estabelecimento de um canal de debate e divulgação de pesquisas originais na grande área das Ciências Sociais Aplicadas, apoiada tanto nos Grupos de Pesquisa estabelecidos no PPGE, quanto em pesquisadores vinculados a organismos nacionais e internacionais. A missão dos Cadernos CEPEC se articula com a solidificação e desenvolvimento do Programa de Pós-graduação em Economia (PPGE), estabelecido no ICSA.

A linha editorial dos Cadernos CEPEC recepciona textos de diferentes matizes teóricas das ciências econômicas e sociais, que busquem tratar, preferencialmente, das inter-relações entre as sociedades e economias amazônicas com a brasileira e mundial, seja se utilizando de instrumentais históricos, sociológicos, estatísticos ou econométricos. A linha editorial privilegia artigos que tratem de Desenvolvimento social, econômico e ambiental, preferencialmente focados no mosaico que constitui as diferentes "Amazônias", aceitando, porém, contribuições que, sob enfoque inovador, problematize e seja propositivo acerca do desenvolvimento brasileiro e, ou mesmo, mundial e suas implicações.

Nosso enfoque central, portanto, refere-se ao tratamento multidisciplinar dos temas referentes ao Desenvolvimento das sociedades Amazônicas, considerando que não há uma restrição dessa temática geral, na medida em que diversos temas conexos se integram. Vale observar que a Amazônia Legal Brasileira ocupa aproximadamente 5,2 milhões de $\mathrm{Km} 2$, o que corresponde a aproximadamente $60 \%$ do território brasileiro. Por outro lado, somente a Amazônia brasileira detém, segundo o último censo, uma população de aproximadamente 23 milhões de brasileiros e constitui frente importante da expansão da acumulação capitalista não somente no Brasil, como em outros seis países da América do Sul (Colômbia, Peru, Bolívia, Guiana, Suriname, Venezuela), o que a torna uma questão central para o debate da integração sul-americana.

\section{Instruções para submissão de trabalhos}

Os artigos em conformidade a linha editorial terão que ser submetidos aos editorialistas, em Word, com no máximo 25 laudas de extensão (incluindo notas de referência, bibliografia e anexos). Margens superior e inferior de 3,5 e direita e esquerda de 2,5. A citação de autores deverá seguir o padrão seguinte: (Autor, data, página), caso haja mais de um artigo do mesmo autor no mesmo ano deve-se usar letras minúsculas ao lado da data para fazer a diferenciação, exemplo: (Rivero, 2011, p. 65 ou Rivero, 2011a, p. 65).

Os autores devem fornecer currículo resumido. O artigo deverá vir obrigatoriamente acompanhado de Resumo de até no máximo 25 linhas e o respectivo Abstract 


\section{SUMÁRIO}

1 INTRODUÇÃO 6

2 RESTRIÇÕES NACIONAIS E A QUESTÃO DA VULNERABILIDADE EXTERNA ..... 6

3 PADRÃO EXPORTADOR E VULNERABILIDADE EXTERNA ……………………..... 8

4 A INSERÇÃO PARAENSE NA BALANÇA COMERCIAL BRASILEIRA …………….. 16

5 IMPACTOS DA BASE EXPORTADORA NA DINÂMICA LOCAL DO ESTADO DO

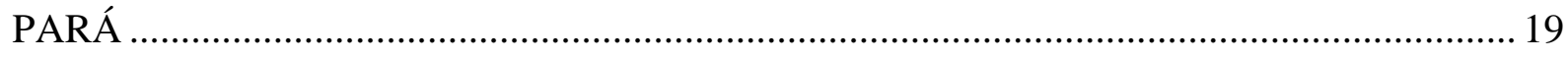

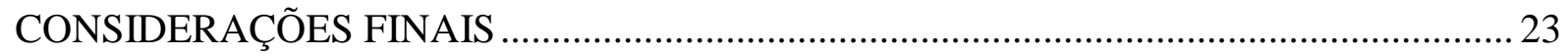

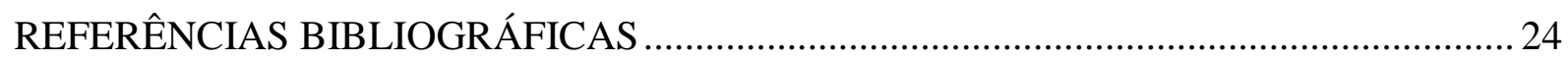




\title{
O comércio exterior brasileiro e a questão regional: elementos da dinâmica econômica do estado do Pará nas duas últimas décadas
}

\author{
Nathalya Rocha ${ }^{1}$ \\ José Raimundo B. Trindade ${ }^{2}$
}

\begin{abstract}
Resumo: O objetivo deste artigo foi o de analisar o comportamento da balança comercial brasileira no período 1995 a 2010, pelos dados do Ministério do Desenvolvimento, Indústria e Comércio Exterior (MDIC). Pretendeu-se também relacionar a questão regional no avanço da balança comercial brasileira no período em questão, e de que forma o estado do Pará interfere nos indicadores da balança comercial e quais os impactos sobre a dinâmica local. Utilizou-se como variáveis dados de exportações, importações, balança comercial e Produto Interno Bruto (PIB). Os resultados apontaram que nos últimos anos, o Brasil tem percebido fatores que colaboraram em parte para a redução da vulnerabilidade externa, como a redução da dívida externa, o dinamismo do setor exportador, que colaborou para a entrada de divisas e o acúmulo de reservas internacionais, mas desde 1990 o país promoveu um amplo processo de liberalização e desregulamentação da economia nacional, expondo-a a competição internacional no bojo do processo de globalização econômica. No âmbito regional, as estratégias nacionais para promover o desenvolvimento regional conceberam ao estado do Pará projetos intensivos em capital baseados em um modelo de desenvolvimento desequilibrado, voltados à demanda do mercado internacional.
\end{abstract}

Palavras-chaves: Importação, Exportação, Balança Comercial, Desenvolvimento Desequilibrado.

Brazilian foreign trade and regional question: economic dynamics of the Pará State in the last decade

Abstract: The objective of this article was to analyze the behavior of the Brazilian trade balance in the period from 1995 to 2010, according to data from the Ministry of Development, Industry and Foreign Trade (MDIC). It was intended to also link the issue in advance of regional Brazilian trade balance in the period in question, and in what way the state of Pará interfere in the indicators of the trade balance and the impacts about the local dynamic. It was used as variables data exports, imports, trade balance and Gross Domestic Product (GDP). The results indicated that in the last years, Brazil has noticed factors that contributed in part to the reduction of external vulnerability, such as debt reduction, the dynamism of the export sector, which contributed to the entry of foreign currency and the accumulation of international reserves, but since 1990 the country has promoted a broad process of liberalization and deregulation of the economy, exposing it to international competition in the midst of the process of economic globalization. At the regional, national strategies for promoting regional development conceived the state of Pará in capital intensive projects based on a model of unbalanced development, focused on the international market demand.

\section{Key words: Import, Export, Trade Balance, Unbalanced Development.}

\footnotetext{
${ }^{1}$ Mestranda do Programa de Pós-graduação em Economia da Universidade Federal do Pará (PPGE/UFPa).

${ }^{2}$ Professor do Programa de Pós-graduação em Economia da Universidade Federal do Pará (PPGE/UFPa).
} 


\section{INTRODUÇÃO}

O Brasil realizou um significativo processo de liberalização cambial-financeira na década de $1990^{3}$, apesar de não apresentar condições necessárias para tal liberalização. Essa política trouxe como resultado apreciação cambial e maior exposição externa da economia nacional, determinados em grande parte, pelo processo de globalização financeira. Isto fez com que o Brasil aprofundasse a vulnerabilidade externa da sua economia no contexto do processo de globalização na esfera financeira durante aquela década.

Este trabalho objetiva analisar o comportamento da balança comercial brasileira no período 1995 a 2010, pelos dados do Ministério do Desenvolvimento, Indústria e Comércio Exterior (MDIC), buscando evidenciar a questão da vulnerabilidade externa Brasileira, ocasionada pelo processo de abertura comercial da sua economia, bem como dos impactos da inserção das economias regionais como o Estado do Pará nesse processo.

Este artigo está dividido em seis seções, incluindo esta introdução. As seções 2 e 3 destinam-se a discutir a relação entre vulnerabilidade externa e a dinâmica econômica nacional, buscando estilizar o comportamento do comércio exterior brasileiro, através de estatística descritiva, utilizando-se dados da balança comercial brasileira, obtidos mediante pesquisa no banco de dados do Ministério do Desenvolvimento, Indústria e Comércio Exterior (MDIC). As seções 4 e 5 tratam da inserção paraense nesse padrão exportador e seus impactos sobre a dinâmica econômica estadual. Por fim, na última seção serão apresentadas as conclusões sobre o tema analisado.

\section{RESTRIÇÕES NACIONAIS E A QUESTÃO DA VULNERABILIDADE EXTERNA}

Vulnerabilidade externa, segundo Gonçalves (2005, p.19) é a baixa capacidade de resistência das economias nacionais a choques e desequilíbrios externos. Nesse sentido, uma economia reduz sua capacidade de resistência frente a fatores externos quando possui elevada dependência de capitais estrangeiros ou fluxos econômicos sob pequena capacidade de controle local, ou fragilidade financeira externa. Tal vulnerabilidade decorre, segundo Gonçalves (1996), do grau de abertura, bem como das formas de abertura, que são incompatíveis com a realidade, como por exemplo, da economia brasileira. Entretanto, a questão da vulnerabilidade externa não se restringe à capacidade de resistência, uma vez que

\footnotetext{
${ }^{3}$ Para mais detalhes ver Gonçalves (2005), Beluzzo e Carneiro (2003).
} 
existem os problemas quanto as opções e dos custos de se contrapor à influência das variáveis externas.

Desta forma, a vulnerabilidade tem duas dimensões igualmente importantes: uma envolvendo as opções de respostas com os instrumentos de políticas macroeconômicas disponíveis, e outra que incorpora os custos de enfrentamento ou de ajuste frente aos eventos externos (JONES, 1995, p.7 apud GONÇALVES, 1996). Assim, a vulnerabilidade externa engloba os custos negativos da resistência aos efeitos negativos da volatilidade dos fluxos financeiros, do investimento e do comércio internacionais. Esta resistência é geralmente exercida com o uso de politicas macroeconômicas tradicionais como as políticas monetária, cambial e fiscal. Agindo de outra forma, os governos podem usar tanto controles diretos sobre fluxos de capital, como a politica comercial para enfrentar os problemas criados pela volatilidade dos fluxos internacionais.

A vulnerabilidade externa se manifesta também quando o sistema financeiro doméstico fica com ativos e passivos denominados em moeda estrangeira. Dessa forma, aumenta-se a fragilidade do sistema financeiro nacional que, além das mudanças internas, passa a sofrer a influência e o impacto de mudanças, por vezes, abruptas no investimento internacional e torna-se mais sensível às alterações da taxa de câmbio. Assim, a vulnerabilidade externa é tão maior quanto menor for o conjunto de opções de política de ajuste, e quanto maiores os custos do processo de ajuste. Ou seja, a vulnerabilidade externa varia inversamente com as opções de ajuste e diretamente com os custos do ajuste.

Vale observar, ainda, que um dos aspectos pouco referenciados no debate sobre a vulnerabilidade externa consiste nos impactos ou na interação entre os fatores de vulnerabilidade da economia nacional e de acomodação das economias regionais àquele processo. Assim, como se buscará mostrar, pode-se evidenciar um fator de vulnerabilidade externa regional, tratando-se da maior ou menor capacidade que certa região ou local subnacional tem de influenciar positiva ou negativamente no desempenho do setor externo nacional, por outro a maior ou menor interação entre as condições de desenvolvimento local e o grau de internacionalização da subeconomia regional (TRINDADE \& OLIVEIRA, 2011, 2012).

A vulnerabilidade externa no âmbito comercial $^{4}$ refere-se ao grau de abertura da economia nacional, relacionando-se as necessidades e características das importações, em

\footnotetext{
${ }^{4}$ A noção de vulnerabilidade externa trata do grau de maior ou menor poder de resiliência de uma economia a pressões, fatores desestabilizadores e choques externos. Essa noção é plenamente ajustável a categoria sócio estrutural de dependência, vista enquanto atributo dialético central para se pensar as articulações entre as
} 
contraposição ao grau de competividade das exportações, considerando o perfil dos bens exportados. A integração comercial entre os países é um aspecto marcante da dinâmica de globalização, como já observado anteriormente. Mesmo considerando que o grau de abertura das diversas economias seja contrastante, inclusive pelas características estruturais das mesmas. Corretamente o estudo do Ipea (2010a, p.151-152) destaca, com base em teorias clássicas, a "longeva" tradição que conecta crescimento e comércio internacional que como pode ser visualizado na tabela abaixo confirma a forte interação entre dinâmica exportadora e poder econômico efetivo no Sistema Mundo Capitalista.

Tabela 1 - Participação nas exportações globais (US\$ correntes) de bens (em \%)

\begin{tabular}{lcccc}
\hline & $\mathbf{1 9 9 0}$ & $\mathbf{1 9 9 5}$ & $\mathbf{2 0 0 0}$ & $\mathbf{2 0 0 8}$ \\
\hline Economias avançadas & 80,1 & 76,9 & 72,6 & 63 \\
G7 & 53,4 & 48,8 & 45,7 & 36,5 \\
União Européia & 42,6 & 38,8 & 38,1 & 38,2 \\
NICs asiáticos & 6,4 & 8,2 & 8,3 & 7,3 \\
Economias em desenvolvimento & 19,9 & 23,1 & 27,4 & 37 \\
Asia em desenvolvimento & 5,4 & 7,7 & 9,4 & 14,1 \\
América Latina e Caribe & 3,4 & 3,5 & 4,8 & 4,3 \\
Europa central e oriental & 1,8 & 1,6 & 1,9 & 3,4 \\
Africa & 2,7 & 2 & 2 & 2,7 \\
Oriente Médio & 4,2 & 2,8 & 4 & 5,6 \\
\hline
\end{tabular}

Fonte: World Trade Organization (WTO). Adaptado de Ipea (2010a).

\section{PADRÃO EXPORTADOR E VULNERABILIDADE EXTERNA}

A balança comercial brasileira, por sua vez, apresentou comportamento variado nas últimas duas décadas. Superavitária no começo dos anos 1990 e de 1995 a 2000 deficitária. A partir daí o que se observa é superávit e crescimento considerável do saldo comercial, com as exportações crescendo em ritmo mais acelerado que as importações. Chegou ao pico em 2006, com saldo de US\$ 46,5 bilhões, diminuindo o ritmo depois disso. A análise da Tabela 4 abaixo permite distinguir alguns importantes elementos da trajetória macroeconômica brasileira das últimas décadas. Como ressaltou Conceição Tavares em sua obra clássica (1977, reedição Ipea, 2010, p. 120-121), o "problema estratégico" colocado à economia brasileira diz respeito ao desafio da superação do "estrangulamento externo", sendo que os

diversas formações econômicas capitalistas e o poder de autonomia relativa de cada uma sobre o Sistema-mundo capitalista. A vulnerabilidade externa em termos econômicos poderá se manifestar nas dimensões financeira, comercial, tecnológica e produtivo-real (GONÇALVES, 2005, p. 14). 
diversos momentos conjunturais expressam formatos distintos de política econômica de enfrentamento daquele desafio.

Tabela 2 - Exportação, Importação e Saldo da BC (Brasil) - em US\$ Milhões

\begin{tabular}{rrrc}
\hline Ano & Exportação & Importação & Saldo comercial \\
\hline 1990 & $31.413,8$ & $20.661,4$ & $10.752,4$ \\
1991 & $31.620,4$ & $21.040,5$ & $10.580,0$ \\
1992 & $35.793,0$ & $20.554,0$ & $15.239,0$ \\
1993 & $38.554,8$ & $25.256,0$ & $13.298,8$ \\
1994 & $43.545,1$ & $33.078,7$ & $10.466,5$ \\
1995 & $46.506,3$ & $49.971,9$ & $-3.465,6$ \\
1996 & $47.747,0$ & $53.346,0$ & $-5.599,0$ \\
1997 & $52.986,0$ & $59.840,0$ & $-6.854,0$ \\
1998 & $51.120,0$ & $57.714,0$ & $-6.594,0$ \\
1999 & $48.013,0$ & $49.302,0$ & $-1.289,0$ \\
2000 & $55.119,0$ & $55.851,0$ & $-732,0$ \\
2001 & $58.287,0$ & $55.602,0$ & $2.685,0$ \\
2002 & $60.439,0$ & $47.243,0$ & $13.196,0$ \\
2003 & $73.203,0$ & $48.326,0$ & $24.877,0$ \\
2004 & $96.678,0$ & $62.836,0$ & $33.842,0$ \\
2005 & $118.529,0$ & $73.600,0$ & $44.929,0$ \\
2006 & $137.808,0$ & $91.343,0$ & $46.465,0$ \\
2007 & $160.649,0$ & $120.621,0$ & $40.028,0$ \\
2008 & $197.942,0$ & $173.197,0$ & $24.745,0$ \\
2009 & $152.995,0$ & $127.647,0$ & $25.348,0$ \\
2010 & $201.915,0$ & $181.649,0$ & $20.266,0$ \\
2011 & $256.039,6$ & $226.236,1$ & $29.803,5$ \\
\hline
\end{tabular}

Fonte: MDIC/Secex, 2012.

Durante a década de 1990 o grau de abertura ${ }^{5}$ da economia brasileira se estabilizará em torno de $18 \%$, mesmo patamar da década anterior, somente ocorrendo nova inflexão nesta primeira década do século XXI, quando o grau de abertura da economia brasileira saltará para $26 \%$ em média, resultante do crescimento tanto das exportações quanto das importações: entre 1999 e 2009 tanto exportação quanto importação mais que triplicaram, porém como se destacará a seguir, as características da pauta exportadora ensejam grandes preocupações, as quais remetem, ao problema da elevação da vulnerabilidade externa e suas repercussões.

A dinâmica econômica brasileira e latino-americana a partir da década de 1990 aprofundaram as precárias condições de desenvolvimento autônomo de suas economias

\footnotetext{
${ }^{5}$ Para análise do grau de abertura $([(\mathrm{X}+\mathrm{M}) / \mathrm{PIB}] \%)$ da economia brasileira nas últimas décadas e comparação com outros países conferir Baumann et al. (2010).
} 
nacionais, seja pela desnacionalização de segmentos expressivos da indústria, seja pela elevação da vulnerabilidade externa nos principais aspectos a ser considerados: na capacidade produtiva (elevação das ECE e maior dependência de investimento externo direto), tecnológica (baixa capacidade de estruturação de um sistema nacional de inovação e baixa dinâmica tecnológica) e financeira (investimentos financeiros, empréstimos e financiamentos).

Vale frisar que as específicas condições econômicas enfrentadas na década de 90, foi fruto da consolidação do padrão neoliberal de reprodução econômica, com a redução do papel do Estado na economia e liberalização comercial. Esse quadro ficou ainda mais agravado com as decisões de política cambial encetadas na segunda metade da década de 1990: a apreciação cambial tinha como objetivo o uso das importações como mecanismo de trava da retomada da espiral inflacionária, o que determinou a geração de déficits comerciais desde o ano de 1995 até 2000. Nesse período as contas externas foram problemáticas, especialmente a balança de serviços e rendas, que engloba remessa de lucros, dividendos e royalties e juros principalmente. Em função do Real $(\mathrm{R} \$)$ apreciado e das elevadas taxas de juros, o quadro de déficit foi crescente. Somado a isso os números negativos da balança comercial, temos a caracterização de um quadro cujo agravamento descortinava a possível falência da capacidade de financiamento externo brasileiro, o que de fato se deu em 1999 com a crise cambial brasileira.

Nos últimos dez anos observa-se elevação do grau de abertura da economia brasileira, com elevação no valor exportado bastante significativo: entre 1999 e 2009 o crescimento absoluto é acima de US\$ 100 bilhões, sendo que se triplica o total exportado. Essa trajetória de expansão na exportação foi basicamente centrada na elevação do "quantum" exportado de produtos primários, o que denota e recoloca a velha questão da "dependência externa", na medida em que tal elevação responde basicamente a estímulos de desenvolvimento de economias forâneas que requerem uma expressiva quantidade de bens primários, especificamente neste caso estimulado pelo "boom" da China. 


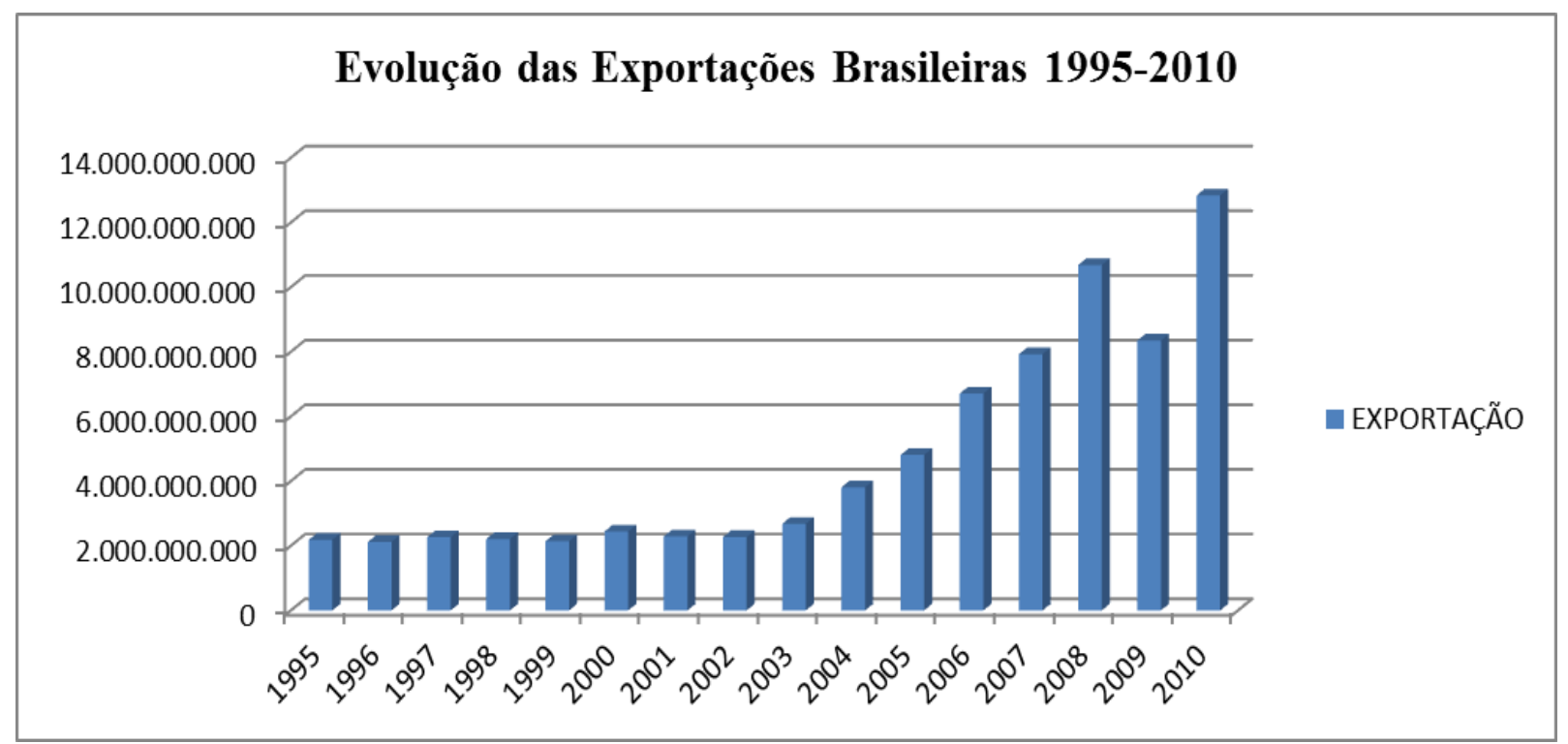

Fonte: Banco Central, Aliceweb-Cacex.

Gráfico 1: Evolução das exportações brasileiras, entre 1995 a 2010

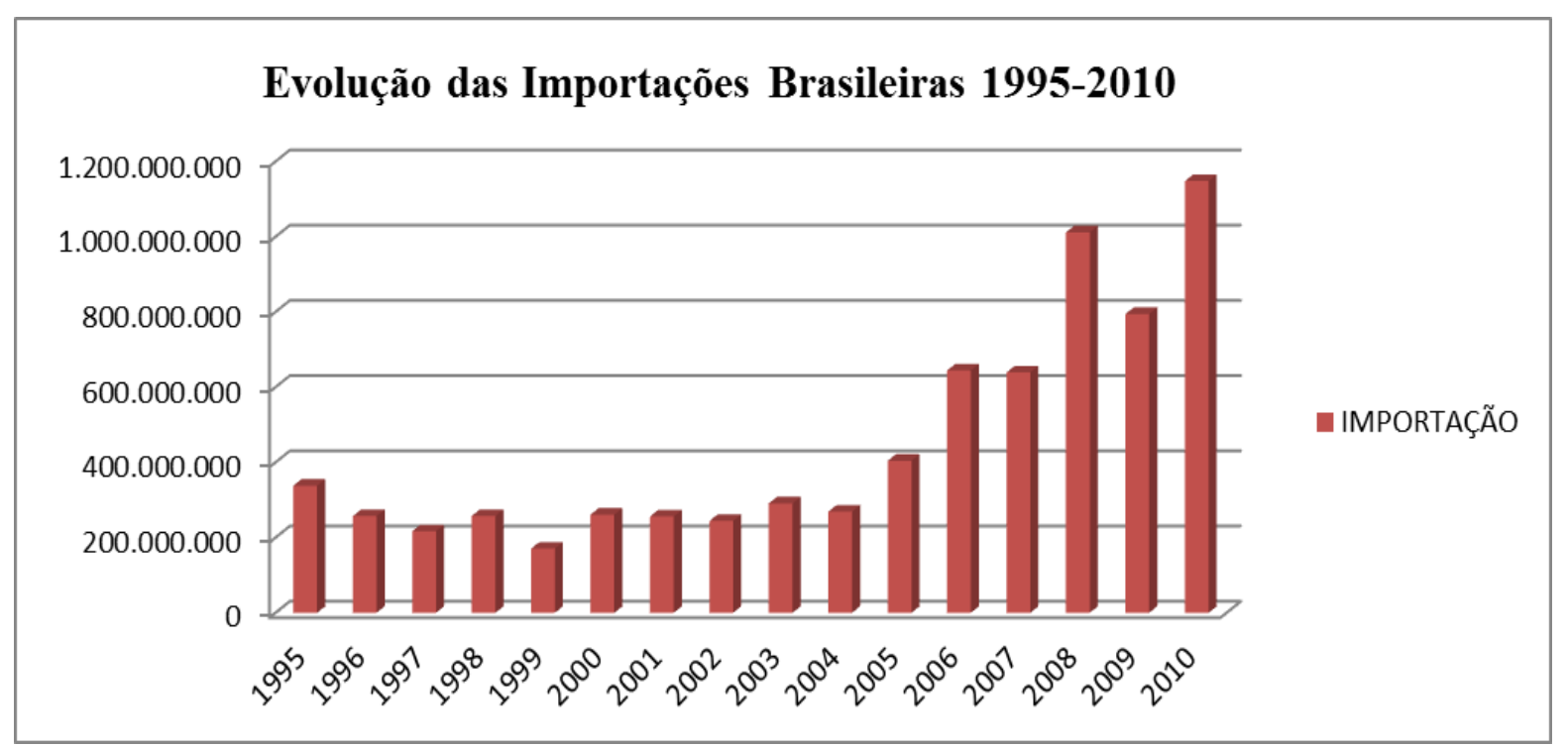

Fonte: Banco Central, Aliceweb-Cacex.

Gráfico 2: Evolução das importações brasileiras, entre 1995 a 2010

A partir de meados de 2002, as exportações brasileiras começaram a acelerar fortemente, registrando recordes históricos mês a mês, em magnitude que levou o saldo em transações correntes a valores próximos ao equilíbrio. Vale destacar que tal processo ocorreu mesmo havendo um choque adverso significativo sobre as contas externas brasileiras, representado pela crise argentina. Dessa forma, mesmo com a apreciação cambial desde o último trimestre de 2002, as exportações não só mantiveram, mas também aceleraram seu crescimento, um resultado a priori inesperado. Apesar do câmbio estar progressivamente mais favorável, as importações somente começaram a reagir a partir de 2004, apesar de 
apresentar um crescimento menor do que as exportações. Com isso, os resultados comerciais continuaram a expandir-se, consolidando-se uma sequência de superávits nas transações correntes.

As exportações brasileiras atingiram o valor recorde de US\$ 118,3 bilhões em 2005, superando a meta de US\$ 117 bilhões previstos pelo Governo. Sobre 2004, as exportações evoluíram 22,6\%, uma taxa superior ao crescimento do comércio mundial de $14 \%$. As importações brasileiras também seguiram ritmo sustentável de crescimento, contabilizando US\$ 73,5 bilhões, em 2005, contra US\$ 62,8 bilhões anotados em 2004, o que representou ampliação de 17,1\%. Já em 2010, o comércio exterior brasileiro registrou nova corrente de comércio recorde de US\$383,6 bilhões, com ampliação de 36,6\% sobre 2009, quando atingiu US\$ 280,7 bilhões. As exportações encerraram o período com valor de US\$201,9 bilhões e as importações de US\$ 181,6 bilhões, resultados igualmente recordes. Em relação a 2009, as exportações apresentaram crescimento de $32,0 \%$ e as importações de 42,2\%. Estes crescimentos significativos indicam a retomada das vendas externas brasileiras e a recuperação da economia nacional, após a crise econômica global de 2009. Ainda em 2009, o fluxo de comércio de exportação e de importação sofreu decréscimo em relação à expansão verificada em alguns meses do ano, em razão da crise financeira internacional, que levou a uma redução dos preços internacionais de commodities agrícolas e minerais e da demanda por bens.

A década de 2000 apresentou um fator novo e de forte repercussão o comércio internacional com a China, sendo que sua explosiva demanda por produtos básicos e matériasprimas estratégicas, tem como efeito a escalada dos preços desses bens. A economia brasileira se nutriu momentaneamente do ciclo chinês, sustentando expressivos superávits comerciais, o que aliviou e estabilizou o balanço de pagamentos na segunda metade da década, ao mesmo tempo em que aprofundou os atávicos dilemas do processo de reprimarização da economia.

Vale observar que o aumento nas importações decorre da retomada do crescimento a partir da segunda metade da década de 2000, puxado, principalmente, pela elevação da renda dos setores mais populares e pelo investimento público. Mais recentemente, a partir, de 2005 observa-se uma recomposição na taxa de investimento industrial privado, com uma breve elevação na FBCF (formação bruta de capital fixo), porém perdendo o fôlego nos anos de 2011 e 2012 apesar da importante redução da taxa real de juro a partir de 2011. Vale ponderar, ainda, que o crescimento das importações também pode estar relacionado com a maior liquidez e o menor custo do capital de empréstimo, que contribuíram para a expansão do crédito em condições mais favoráveis para o consumo e para o financiamento do 
investimento, promovendo o aquecimento da economia brasileira. Ou pelo fato da indústria nacional estar crescendo, impulsionada pelo dinamismo das exportações, uma vez que necessidade de insumos industriais e de bens de capital importados para suportar esse crescimento tem contribuído para o aumento das importações.

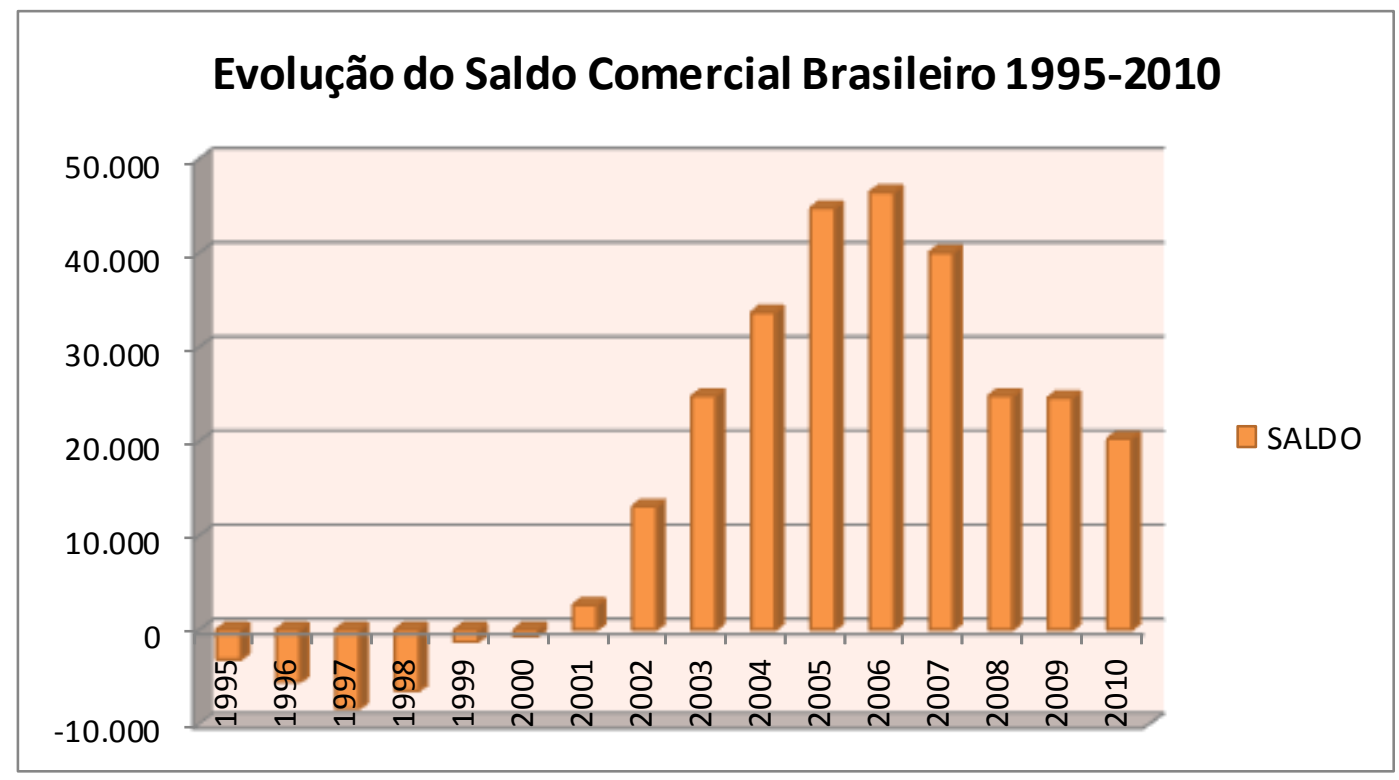

Fonte: Banco Central, Aliceweb-Cacex.

Gráfico 3: Evolução dos saldo comercial brasileiro, entre 1995 a 2010

O saldo comercial fechou 2005 com superávit de US\$ 44,8 bilhões, valor $33 \%$ superior ao contabilizado em 2004, quando atingiu US\$ 33,7 bilhões. Este crescimento do saldo comercial ocorreu em um cenário de expansão das importações. O saldo comercial atingiu US\$ 24,7 bilhões em 2008, valor menor que o registrado em 2007, de US\$ 40,0 bilhões, devido ao maior dinamismo das importações frente às exportações, explicado em grande medida pela valorização da moeda nacional e pelo crescimento da economia brasileira. O saldo comercial atingiu US\$ 20,3 bilhões em 2010, significando retração de 19,8\% sobre o consignado em 2009, de US\$25,3 bilhões, motivado por um maior aumento das importações em relação às exportações.

Entretanto, aspecto central a ser analisado refere-se a qualidade estrutural dessa base exportadora. Assim, como mostra o Gráfico abaixo, desde 1995 a participação de produtos básicos (conforme MDIC) vem crescendo comparativamente a menor participação de produtos industrializados. Estudos realizados pela CEPAL/Ipea (OLIVEIRA, LEÃO e CHERNAVSKY, 2010, p. 87) mostram que na pauta de exportação brasileira, a participação de bens de baixa intensidade tecnológica e primários sempre foi predominante, "flutuando ao 
longo de todo período (1995/2006) entre $35 \%$ e $44 \%$, percentual alcançado no último ano (2006) analisado". Desde 2000, a relação exportação básicos/industrializados cresceu e essa tendência parece se agravar nos últimos cinco anos (2008/2012).

Considerando o período 1995-2011, o gráfico abaixo mostra que até o ano de 2003 a relação básicos/industrializados era menor que 0,5 , o que significa dizer que os produtos industrializados representavam parcela maior das exportações. A partir de 2004 percebe-se uma inversão, quando as vendas ao exterior de produtos básicos só aumenta sua participação com o passar do tempo.

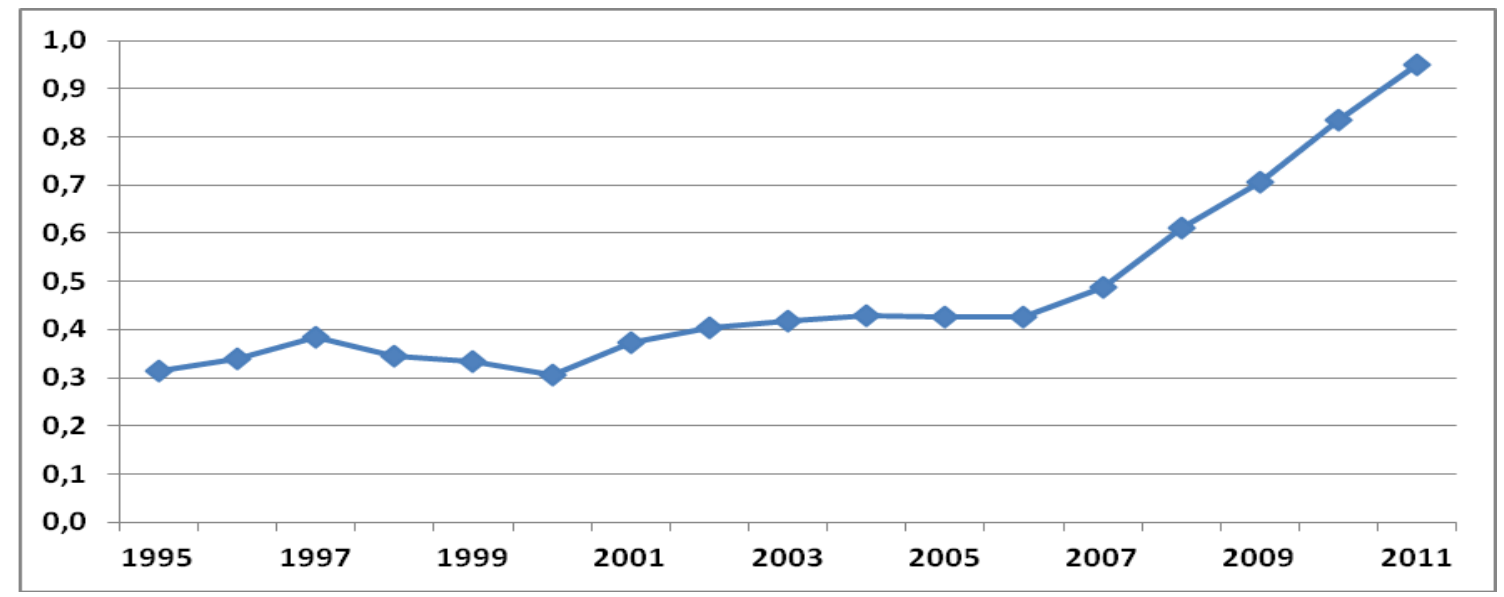

Fonte: MDIC (2012). Extraído de Trindade \& Oliveira (2011, 2012).

Gráfico 4 - Relação exportação produtos básicos/industrializados - Brasil, 1995-2011

Dado que os setores da agropecuária e mineração tiveram mais forte crescimento nos últimos anos, como mostra a tabela abaixo, os principais produtos exportados pelo país em 2011 e 2012 são produtos básicos. Dentre eles o minério de ferro é o principal item da pauta de exportação, seguido por óleos e produtos de soja. E, mesmo não estando (ainda) na lista, a carne bovina é outro item em franca ascensão. Em 2011, o Brasil exportou US\$ 5,4 bilhões em carne bovina (aproximadamente $80 \%$ in natura). Vale ressaltar que o país é o maior exportador mundial de carne bovina. 
Tabela 3 - Principais produtos exportados pelo Brasil (2011)

\begin{tabular}{lrr}
\hline Descrição NCM & US\$ (Mil) & \multicolumn{1}{c}{ \% } \\
\hline MINERIOS DE FERRO NAO AGLOMERADOS E SEUS CONCENTRAI & 31.851 .797 & 12,44 \\
OLEOS BRUTOS DE PETROLEO & 21.603 .300 & 8,44 \\
OUTROS GRAOS DE SOJA,MESMO TRITURADOS & 16.312 .232 & 6,37 \\
ACUCAR DE CANA,EM BRUTO & 11.548 .786 & 4,51 \\
MINERIOS DE FERRO AGLOMERADOS E SEUS CONCENTRADOS & 9.965 .454 & 3,89 \\
CAFE NAO TORRADO,NAO DESCAFEINADO,EM GRAO & 7.999 .955 & 3,12 \\
BAGACOS E OUTS.RESIDUOS SOLIDOS,DA EXTR.DO OLEO DE SO. & 5.544 .358 & 2,17 \\
PASTA QUIM.MADEIRA DE N/CONIF.A SODA/SULFATO,SEMI/BRA & 4.605 .115 & 1,80 \\
PEDACOS E MIUDEZAS,COMEST.DE GALOS/GALINHAS,CONGELA & 4.454 .340 & 1,74 \\
CARNES DESOSSADAS DE BOVINO,CONGELADAS & 3.506 .284 & 1,37 \\
Outros & 138.647 .953 & 54,15 \\
\hline Total & $\mathbf{2 5 6 . 0 3 9 . 5 7 5}$ & $\mathbf{1 0 0 , 0 0}$ \\
\hline
\end{tabular}

Fonte: MDIC (2012).

Como destacaram Belluzo e Almeida $(2011,2012)$ os "resultados da balança comercial mostram uma descomunal aceleração do déficit da indústria de transformação", com paulatino reforço da pauta primário exportadora, como se evidenciam nos indicadores expostos. Tem-se, então, para o Brasil, que em termos absolutos a exportação de produtos industrializados ainda é maior que a de básicos, porém este vem crescendo e aumentando sua participação relativa a cada ano na pauta de exportação do país, com notórias implicações macroeconômicas quanto aos aspectos de apreciação cambial e a trajetória de desindustrialização pior que já teve.

O gráfico anterior mostra a relação básicos/industrializados, ou seja, o quanto o primeiro representa do segundo. No primeiro ano o índice foi de 0,31 , ou seja, em $1995^{6}$ os básicos representavam cerca de um terço dos industrializados. Ao longo dos últimos quinze anos, o índice vem elevando-se, chegando a 0,95 no último ano da série. No caso de regiões economicamente mais atrasadas, como a Amazônia brasileira, por exemplo, este coeficiente é ainda mais dramático (3,12 no ano de 2010), pois a pauta de exportação é ainda mais significativamente centrada em bens básicos, denotando o elevado grau de vulnerabilidade externa dessas regiões.

A dinâmica exportadora revela que em quanto no período de dez anos (1999/2009) a exportação global cresceu aproximadamente $318 \%$, a exportação especificamente de bens primários cresceu em 525\%, o que fez com que em 2011 sua participação relativa na pauta

\footnotetext{
${ }^{6}$ Boa parte das séries aqui utilizadas começa em 1995. A motivação para tal escolha é trabalhar com dados a partir da implantação do Plano Real (mesmo os valores das transações terem o dólar como unidade monetária).
} 
exportadora significasse quase metade da mesma (47,80\%), como denotado nos dados mostrados na tabela abaixo.

A geração de divisas em anos recentes está pautada, principalmente, na comercialização de produtos básicos. Mais ainda, a balança comercial no país deve sua situação superavitária aos estados menos desenvolvidos do país, localizados principalmente na Amazônia brasileira, especialmente Pará e Mato Grosso. O cenário evidencia importante processo de especialização primária da pauta de exportação, com consideráveis implicações tanto econômicas quanto socioambientais, consistindo o desmatamento um dos principais aspectos daí decorrentes.

\section{A INSERÇÃO PARAENSE NA BALANÇA COMERCIAL BRASILEIRA}

O Estado do Pará nas últimas três décadas se inseriu passivamente no modelo de desenvolvimento nacional primário exportador. A partir da integração da sua economia à estratégia de desenvolvimento nacional, o Estado do Pará passou a se especializar na produção e exportação de produtos minerais, de alta intensidade de capital, e de produtos agroindustriais, voltados para o atendimento do mercado internacional.

A transformação da estrutura econômica paraense não se restringiu, todavia, aos projetos de extração e beneficiamento mineral. Ao contrário, além desses foram implantados inúmeros projetos agroindustriais, agropecuários e madeireiros. Com a implantação e funcionamento desses empreendimentos produtivos, a economia paraense passou a apresentar perfil produtivo e dinâmica de desenvolvimento centrado na base exportadora de produtos principalmente de origem extrativo mineral.

Antes de sofrer essa transformação, os principais produtos exportados ainda eram considerados básicos, sem beneficiamento industrial como: madeira, pimenta-do-reino, castanha, camarão e peixe, até a década de 70. A partir daí, com o início da produção de bauxita, celulose, minério de ferro, manganês, alumínio, alumina e outros, a pauta de exportação referente aos produtos considerados como básicos passou a ser dominado pelo minério de manganês, minério de ferro, caulim e bauxita, enquanto que como semimanufaturados passou a imperar a exportação de alumínio, alumina, celulose, ferro-gusa silício e cobre. É importante ressaltar que devido às características dos projetos instalados, metade dos produtos de origem mineral é considerada básica, sem beneficiamento industrial, enquanto que, apesar de perceber um mínimo de beneficiamento industrial, a outra metade é classificada como produtos semimanufaturados. Com isso, é possível notar que o Estado do 
Pará mudou o perfil da sua produção, mas sem se desvencilhar de sua principal característica: exportador de matérias-primas.

Consequentemente, este novo perfil produtivo contribuiu e ressaltou a situação apresentada pela balança comercial do Estado, uma vez que, quase toda a produção é voltada ao beneficiamento de minérios e outros produtos relevantes que são exportados para o mercado externo, e ainda por uma pequena parcela de produtos oriundos da importação. Isto contribuiu para que o saldo da balança comercial do Pará venha apresentando superávits, de forma permanente e crescente (Tabela 4).

Tabela 4: Balança Comercial do Estado do Pará 1995-2010, em US\$ Milhões.

\begin{tabular}{|c|c|c|c|}
\hline \multicolumn{4}{|c|}{ Balança Comercial do Estado do Pará 1995-2010 } \\
\hline ANO & EXPORTAÇÃ̃O & IMPO ORTA ÇÃ̃O & SALDO \\
\hline 1995 & 2.181 .436 .565 & 338.071 .726 & 1.843 .364 .839 \\
\hline 1996 & 2.117 .178 .431 & 256.966 .832 & 1.860 .211 .599 \\
\hline 1997 & 2.264 .084 .533 & 216.780 .584 & 2.047 .303 .949 \\
\hline 1998 & 2.209 .013 .607 & 257.340 .494 & 1.951 .673 .113 \\
\hline 1999 & 2.135 .959 .720 & 170.846 .778 & 1.965 .112 .942 \\
\hline 2000 & 2.441 .275 .870 & 260.763 .832 & 2.180 .512 .038 \\
\hline 2001 & 2.289 .087 .011 & 255.952 .813 & 2.033 .134 .198 \\
\hline 2002 & 2.266 .867 .807 & 244.064 .074 & 2.022 .803 .733 \\
\hline 2003 & 2.677 .553 .496 & 290.960 .039 & 2.386 .593 .457 \\
\hline 2004 & 3.804 .905 .385 & 268.763 .502 & 3.536 .141 .883 \\
\hline 2005 & 4.807 .893 .461 & 404.403 .705 & 4.403 .489 .756 \\
\hline 2006 & 6.707 .888 .191 & 644.277 .307 & 6.063 .610 .884 \\
\hline 2007 & 7.925 .093 .138 & 639.292 .078 & 7.285 .801 .060 \\
\hline 2008 & 10.680 .513 .954 & 1.011 .682 .601 & 9.668 .831 .353 \\
\hline 2009 & 8.345 .255 .133 & 794.438 .547 & 7.550 .816 .586 \\
\hline 2010 & 12.835 .420 .476 & 1.147 .828 .475 & 11.687 .592 .001 \\
\hline
\end{tabular}

O Produto Interno Bruto (PIB) paraense, no período de instalação e pós-instalação dos empreendimentos produtivos e infraestruturais, evoluiu a taxas elevadas, de maneira crescente e quase que constante, apresentando taxas superiores às da economia brasileira. Apesar deste crescimento do PIB ter sido mais representativo entre os anos 1980 e 1990, em decorrência da implantação da maior parte dos empreendimentos produtivos no Pará, principalmente os do setor mineral, essa evolução do PIB tem se evidenciado relevante ao longo dos anos iniciais do século XXI, como consequência da manutenção e ampliação desses empreendimentos produtivos. Esta evolução é responsável pela posição de destaque do Estado do Pará dentre as unidades federativas que compõem a Região Norte (Gráfico 4).

O PIB do Pará evoluiu a taxas crescentes ao longo dos anos de 1995 a 2008, sendo que em 1995 o PIB de R\$ 10,9 bilhões representou 1,56 \% do PIB total do Brasil, já em 1998 esse percentual caiu para $1,54 \%$, um decréscimo de 0,20 ponto percentual em relação a 1995 . No entanto, no ano de 2002 o percentual de participação do Pará do PIB sofreu um crescimento, 
saltando para 1,74\% (20\% em relação a 1998). Em 2010 a participação do Estado foi de 2,06\%, a maior participação de toda a série (Gráfico 6).

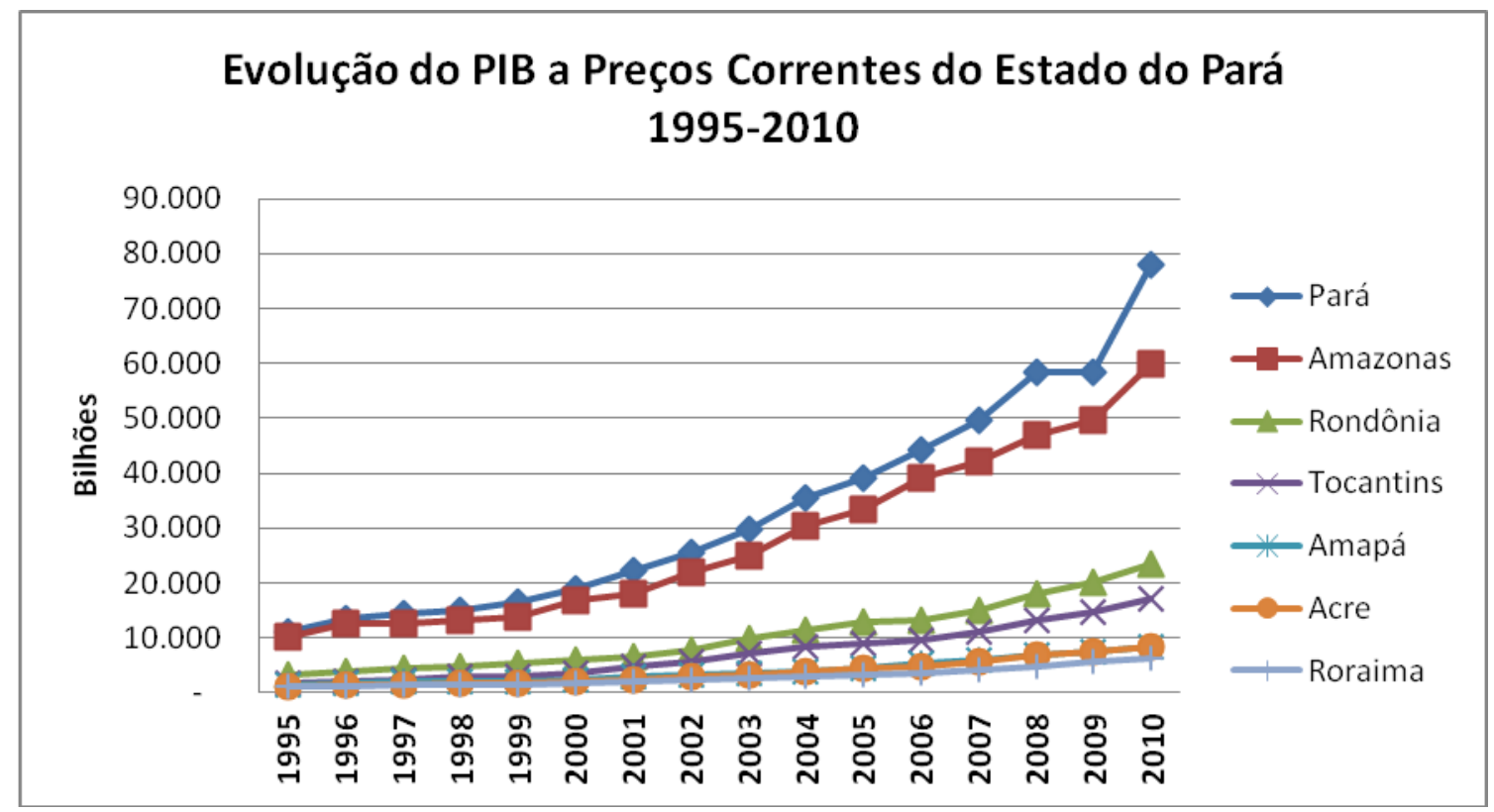

Fonte: IBGE

Gráfico 5: Evolução do PIB dos Estados Amazônicos (1995 a 2010)

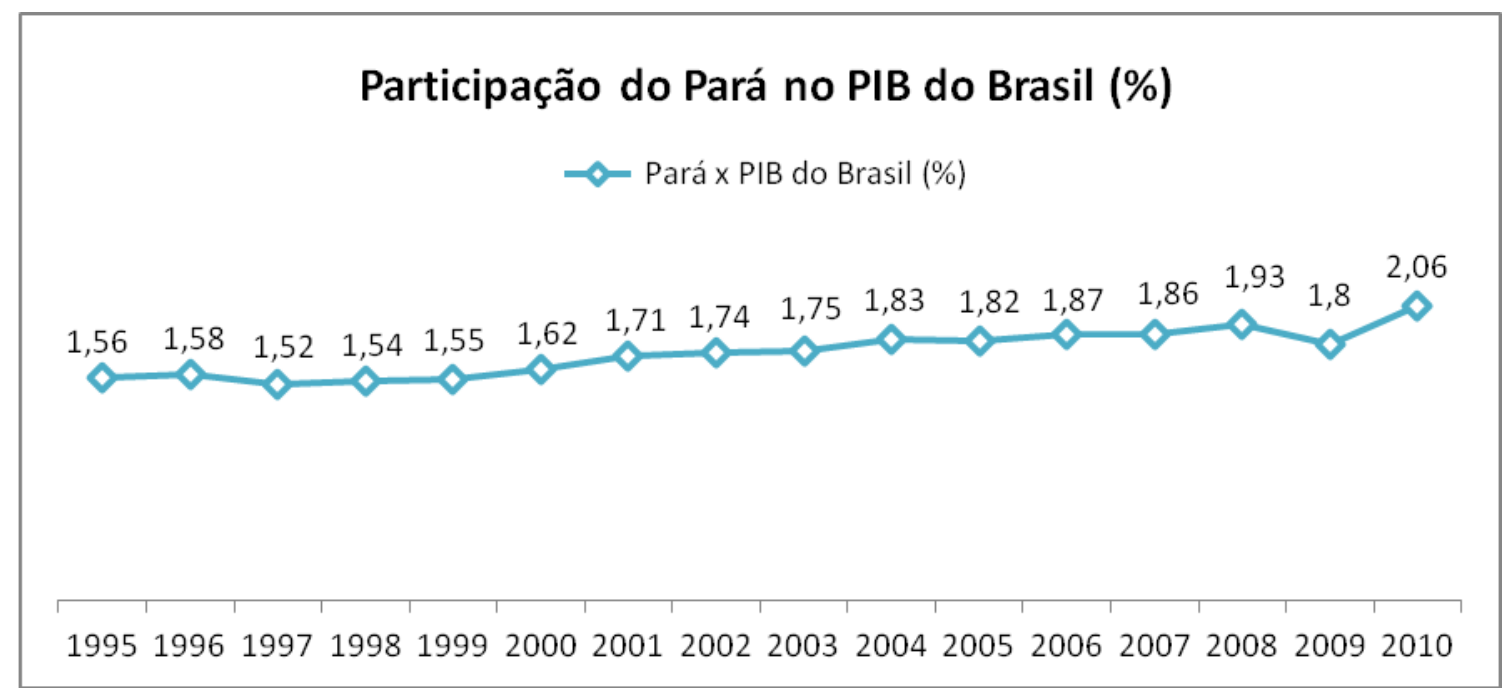

Fonte: IBGE.

Gráfico 6: Participação do Pará no PIB brasileiro 


\section{IMPACTOS DA BASE EXPORTADORA NA DINÂMICA LOCAL DO ESTADO DO PARÁ}

As estratégias nacionais para promover o desenvolvimento regional implantaram, a partir de 1974, na Amazônia, projetos intensivos em capital baseados em um modelo de desenvolvimento desequilibrado, centralizado quase que exclusivamente em atividades e setores produtivos subordinados à demanda do mercado internacional. Os investimentos realizados por esses projetos propiciaram um acelerado ritmo de crescimento da produção regional, comprovado por taxas de crescimento superiores ás taxas verificadas pela economia nacional, o que acabou por contribuir para a desconcentração econômica no País.

Entretanto, tais estratégias inseriram a região num modelo de dependência do mercado nacional. Essas estratégias de desenvolvimento determinaram a inserção da Amazônia no contexto da reprodução do capital em escala nacional e internacional, alterando a configuração da sua estrutura produtiva e reintroduzindo a região no contexto do mercado internacional, em moldes diferentes do passado, mas ainda apoiado em processos de exploração econômica do tipo primário-exportador (LIRA, 2007).

Especificamente, no caso do Pará o início do processo de integração nacional se deu a partir dos anos 50, primeiramente com a transformação do Banco de Crédito da Borracha em Banco de Crédito da Amazônia, em 1950, e, posteriormente, com a criação da Superintendência do Plano de Valorização Econômica da Amazônia - SPVEA, em 1953, baseada no dispositivo criado pela Constituição Federal de 1946, onde se criou um fundo regional composto por 3\% da arrecadação tributária da União, dos Estados e dos Municípios.

Essas instituições contribuíram para a valorização econômica da região, uma vez que ainda não havia uma estratégia nacional de desenvolvimento regional definida.

O II Plano Nacional de Desenvolvimento (II PND) e, no seu bojo, o II Plano de Desenvolvimento para a Amazônia (II PDA), definiu que á região caberia contribuir, por meio do seu desenvolvimento, com o esforço de desenvolvimento nacional, de duas maneiras: a) por meio da ampliação das trocas inter-regionais, suprindo a região mais desenvolvida de matérias-primas e de produtos industrializados regionais; b) mediante contribuições à receita cambial líquida do país, através da geração de dívidas (decorrentes de exportações), da economia de dívidas (pela sua contribuição no processo de substituição de importações de insumos básicos), e da liberação de produção exportável (que estava comprometida pela demanda interna) (SUDAM, 1976; LIRA, 2007).

Essa estratégia de desenvolvimento regional fez com que a Amazônia assumisse o papel de geradora e captadora de recursos externos, transformando-a em uma verdadeira 
"usina de dólares" necessários a continuação do desenvolvimento nacional e do seu modelo de substituição de importações. Entretanto, os projetos econômicos que apresentavam um perfil exportador, em virtude de seus produtos estarem direcionados a abastecer o mercado internacional, e, portanto, vinculados a tal estratégia, encontravam-se quase que exclusivamente previstos para se localizarem no território paraense, uma vez que havia a necessidade da vinculação da localização dos empreendimentos minerais à proximidade das jazidas, da proximidade desses empreendimentos à localização das hidrelétricas previstas para construção, da proximidade de escoamento da produção mineral, agroindustrial e agropecuária às estruturas portuárias previstas para implantação no Pará e Maranhão, com destino ao mercado internacional (BECKER, 1999; LIRA, 2005, TRINDADE, 2001; TRINDADE \& OLIVEIRA, 2011).

Ao ser estabelecido o II PND, foram definidas metas ambiciosas de crescimento da economia nacional, exigindo, contudo, a sua ordenação do espaço nacional, através da desconcentração da indústria nacional e da participação das regiões periféricas na produção industrial. No caso da Amazônia, que apresentava potencialidades econômicas ainda não exploradas, teria que dar sua parcela de contribuição por meio do aumento das exportações de matérias-primas e insumos básicos, garantindo assim a manutenção das altas taxas de crescimento do PIB brasileiro.

Por conta disto, as riquezas minerais e o potencial energético da região assumiram papel fundamental nesse contexto, condicionando o seu aproveitamento econômico por meio de grandes empreendimentos econômicos, que passaram a ser conhecidos como "grandes projetos", dada a magnitude e o tipo de capital investido e o porte dos empreendimentos no contexto da região amazônica. Esta estratégia consolidou-se ainda mais com o aprofundamento da crise econômica brasileira após a eclosão do segundo choque dos preços do petróleo no mercado internacional, combinada com a elevação das taxas de juros americana, em 1979.

A aceleração e a implantação desses projetos na região se intensificaram principalmente após o governo federal ter criado em novembro de 1980 o Programa Grande Carajás - PGC, mais um programa de desenvolvimento regional, com um regime especial de concessão de incentivos fiscais, creditícios e outros, no entanto direcionado tanto para os empreendimentos produtivos quanto para os de infraestrutura física necessária à viabilização econômica desses empreendimentos produtivos, sobretudo os do ramo mineral, em sua área de abrangência. 
A partir das facilidades de financiamento viabilizaram-se economicamente inúmeros projetos, mesmo aqueles que já tinham iniciado o seu processo de implantação, sendo que isto beneficiou diretamente o Pará, visto o raio de abrangência do PGC contemplar, em sua maioria, o território paraense. Nesse sentido, a partir do final dos anos setenta começa a mudar o aspecto da economia paraense, com o início da produção de minerais beneficiados e transformados, voltados a atender o mercado externo.

No final dos anos de 1980 o Pará se consolidou efetivamente como uma economia mineral, retomando a sua integração e vinculação ao mercado internacional, baseada na exportação dos minérios explorados em seu território. Entretanto, esse relevante papel não se restringiu apenas a esses produtos até então produzidos somente no Pará.

A transformação da estrutura econômica paraense não se limitou, somente aos projetos de extração e beneficiamento mineral. Foram implantados, ainda durante esse período, inúmeros projetos agroindustriais, agropecuários e madeireiros.

Com isso, foram-se estruturando e consolidando no Pará três grandes eixos ou polos dinâmicos produtivos (BUARQUE, 1995; LIRA, 2008):

- Os polos minerais: polo Trombetas (bauxita metalúrgica e refratária, no noroeste e centro norte do Estado), polo Carajás (minério de ferro, manganês, ouro, cobre e níquel, no sudeste do Estado), polo aluminífero (alumina e alumínio primário, no norte do Estado), polo siderúrgico (ferro-gusa, ferro-silício manganês, silício metálico e outros, no sudeste do Estado) e polo caulífero (caulim, no noroeste e nordeste do Estado), voltados predominantemente para o mercado internacional;

- O polo agropecuário: com um amplo leque de atividades vinculadas à pecuária, produção de grãos e culturas permanentes, no oeste, leste e sudeste do Pará, tendo a sua produção direcionada para o mercado interno brasileiro e para o mercado internacional;

- O polo madeireiro: com forte atuação ao longo das rodovias PA-150 e Belém-Brasília, no baixo Amazonas e estuário amazônico, no sul, sudeste e oeste do Pará, também direcionando sua produção para o mercado nacional e para o mercado internacional.

Os grandes projetos minerais estabeleceram uma nova disposição setorial na economia paraense, a partir da instalação das plantas de extração mineral de bauxita, hematita e dos poderosos interesses da Vale, em associação com capitais nacionais e estrangeiros. O Pará tornou-se o segundo produtor mineral do país, o que desencadeou modificações sociais e econômicas, particularmente em áreas sub-regionais, com relativas interferências sobre o 
comportamento da macro e da microeconomia do estado ${ }^{7}$. Apesar da queda de $16 \%$ da atividade de mineração em 2009, provocada pela crise econômica mundial, o setor mineral ainda conseguiu exportar U\$ $\$ 4,9$ bilhões contra U\$ $\$ 5,8$ bilhões de 2008, o maior da história.

As exportações paraenses têm crescido substancialmente em anos recentes, mantendo a característica superavitária de sua balança comercial. Conforme mostram os dados do MDIC, em 1996 o Pará era o sétimo maior estado exportador, assumindo a nona posição em 2003. Deste último em diante, as exportações do estado só cresceram (com exceção da queda em 2009), e em 2010 as vendas ao resto do mundo já colocam o Pará como o sexto maior exportador do país, com US\$ 12,8 bilhões em venda ao exterior (com grandes chances de ultrapassar o Paraná nos próximos anos e assumir a quinta colocação); já as importações ficam próximas de US\$ 1,2 bilhão, encerrando o ano de 2010 com saldo de US\$ 11,6 bilhões.

Seria um cenário interessante e de conforto para o Pará não fossem as características intrínsecas a isso. Uma delas é a composição da pauta de exportação paraense, que é composta em mais de $70 \%$ por produtos básicos. O principal produto da pauta de exportação paraense é o minério de ferro, que em 2010 representou mais de 50\% de tudo o que foi exportado pelo estado (ver Tabela 2 ) e mais de $30 \%$ da exportação nacional do produto. $\mathrm{O}$ aumento da demanda do produto no mercado internacional (mesmo com a elevação substancial do preço), principalmente da China, tem aumentado a exportação do produto. $\mathrm{O}$ citado país asiático, por exemplo, foi o destino de $50 \%$ de todo o minério de ferro vendido pelo Pará em 2010.

Tabela 5 - Principais produtos exportados pelo Estado do Pará (2010).

\begin{tabular}{|l|r|}
\hline \multicolumn{1}{|c|}{ Descrição NCM } & US\$ (mil) \\
\hline Minérios de ferro não aglomerados e seus concentrados & 6.900 .531 \\
\hline Alumina calcinada & 1.290 .617 \\
\hline Alumínio não ligado em forma bruta & 898.311 \\
\hline Outros minérios de cobre e seus concentrados & 701.513 \\
\hline Outros bovinos vivos & 618.207 \\
\hline Ferro fundido bruto não ligado, c/peso<=0.5\% de fósforo & 374.905 \\
\hline Outros & 2.051 .338 \\
\hline Total & 12.835 .420 \\
\hline
\end{tabular}

Fonte: MDIC (2011).

\footnotetext{
${ }^{7}$ Para análise de impactos tributários e suas repercussões sobre o desenvolvimento regional vale conferir Monteiro (2004) e Trindade (2011).
} 
Como bem observa estudo realizado pelo IPEA (2010c, p. 29), por mais que a estrutura produtiva brasileira seja hoje industrialmente diversificada, "há que se ressaltar a ampliação nos últimos anos do peso, na estrutura produtiva, dos setores de baixa intensidade tecnológica, como agricultura e serviços, em detrimento da indústria", o que coloca o desafio de "dar prosseguimento à industrialização". Acrescente-se que há uma evidente necessidade de superar os limites de exportação de bens básicos, estimulando uma pauta exportadora que agregue mais valor, dado que a tendência nos últimos anos foi de redução na pauta das exportações dos produtos de maior valor agregado.

Se depender do mercado externo, este cenário poderá se intensificar, pois a demanda por minério de ferro, soja e carne bovina é crescente e não apresenta sinais de mudança. Se a economia mundial superar a crise atual (ainda que de maneira gradativa), a tendência é que o Brasil continue ampliando seu papel de fornecedor mundial dos produtos citados e tenha sua pauta de exportação cada vez mais centrada em produtos básicos. Em suma, a questão aqui levantada precisa ser aprofundada e servir de reflexão e ação, caso se queira uma economia mais industrializada e sustentavelmente desenvolvida, um país com menor desigualdade regional e uma estrutura produtiva em bases diferenciadas e que possibilite romper com um tipo de desenvolvimento voltando a uma economia dominada por agronegócios.

\section{CONSIDERAÇÕES FINAIS}

Ao longo dos últimos anos, o Brasil tem percebido fatores que colaboraram em parte para a redução da vulnerabilidade externa, dentre eles: a redução da dívida externa, o dinamismo do setor exportador, responsável pelo país alcançar saldos positivos na balança comercial e que colaborou para a entrada de divisas, e o acúmulo de reservas internacionais.

Entretanto, no início dos anos de 1990 o Estado brasileiro promoveu um amplo processo de liberalização e desregulamentação da economia nacional, expondo-a a competição internacional no bojo do processo de globalização econômica. Isto impôs, no plano nacional, uma ruptura definitiva com o velho padrão nacional-desenvolvimentista que fomentava o modelo de desenvolvimento nacional presente até meados dos anos oitenta, e no plano regional, uma secundarização da problemática regional no país, passando para um segundo plano as políticas compensatórias que vinham sendo adotadas para enfrentar as desigualdades regionais no país, desde os anos sessenta, deixando de ter sentido os tradicionais mecanismos de desenvolvimento regional. 
Dessa maneira, a política de comércio exterior dos anos 1990 se caracterizou por uma maior abertura ao mercado externo através de redução de tarifas, aumentos tanto nas importações e exportações, e uma maior instrumentalização do comércio internacional por meio da criação de sistemas informatizados de controle aduaneiro.

No âmbito regional, as estratégias nacionais para promover o desenvolvimento regional conceberam ao Estado do Pará projetos intensivos em capital baseados em um modelo de desenvolvimento desequilibrado, voltados quase que exclusivamente para atividades e setores produtivos subordinados à demanda do mercado internacional. Consequentemente, em decorrência dos investimentos realizados por esses projetos, acelerouse o ritmo de crescimento da produção regional, determinando que, nas duas últimas décadas do século XX, as taxas de crescimento econômico do Pará tenham sido superiores percebidas pela economia nacional, contribuindo para a desconcentração econômica no País.

Através deste estudo, foi possível observar que o processo de abertura externa da economia brasileira nos anos de 1990, fez com que se agravasse a vulnerabilidade externa da sua economia, representada seja por desequilíbrios na balança de pagamentos como no aumento do endividamento público. Assim, espera-se que a política de comércio internacional brasileira seja atrelada a dinâmica nacional, uma vez que o grau de abertura comercial deve-se atentar para se intensificar, dada a exigência da dinâmica internacional. Espera-se ainda que o país possa adotar como meta, a redução da vulnerabilidade externa e da dependência da dinâmica capitalista internacional.

\section{REFERÊNCIAS BIBLIOGRÁFICAS}

BELlUZZO, L. G. e CARNEIRO, R. Globalização e Integração Perversa. In Política Econômica em Foco. Boletim Semestral do Centro de Estudos de Conjuntura e Política Econômica do Instituto de Economia. Instituto de Economia, Unicamp. Campinas. №.1, maio/agosto 2003

GONÇALVES, Reinaldo. Globalização financeira e inserção internacional do Brasil. Revista Brasileira de Política Internacional, Rio de Janeiro: Instituto Brasileiro de Relações Internacionais, v. 39, n. 1, p.72-88, 1996;

GONÇALVES, Reinaldo, Globalização e Desnacionalização, Rio de Janeiro, Ed. Paz e Terra, 1999.

GONÇALVES, Reinaldo. Economia Política Internacional: Fundamentos Teóricos e as Relações Internacionais do Brasil. Rio de Janeiro: Elsevier, 2005 
IDESP. ESTAdO DO PARÁ: (Di) Visões Territoriais Perspectivas Sociais, Econômicas, Financeiras e Ambientais. Belém, 2011.

IBGE, Contas Regionais do Brasil 2004-2008. Nov/2010.

LAVINAS, Lena et all. Desigualdades Regionais: Indicadores Socioeconômicos nos Anos 90. Rio de Janeiro: IPEA, fev 1997. (Texto para discussão, 460)

Do aviamento à globalização, facetas do (sub) desenvolvimento da economia paraense. Belém: ANPUR, Simpósio, 2007.

LIRA, Sérgio Roberto Bacury de; SILVA, Márcio Luiz Monteiro da.PINTO, Rosenira Siqueira. Desigualdade e heterogeneidade no desenvolvimento da Amazônia no século XXI. . Nova econ., 2009, vol.19, no.1, p.153-184

NASCIMENTO, E.R., Souza, A.F. de.Uma Breve Análise da Evolução do Balanço de Pagamentos no Brasil.

OLIVEIRA, Júlio César de. Análise do Crescimento Econômico e das Desigualdades Regionais no Brasil.

Taciane Graciele Fanck Kich, Daniel Arruda Coronel ,Kelmara Mendes Vieira. DETERMINANTES DA BALANÇA COMERCIAL DO AGRONEGÓCIO BRASILEIRO: análise da influência das variáveis macroeconômicas no período de 1997 a 2009.1SP, v. 42, n. 4, jul./ago. 2012.

TRINDADE, J. R. B. A metamorfose do trabalho na Amazônia: para além da Mineração Rio do Norte. Belém: UFPA/NAEA, 2001. 171 p.

TRINDADE, J. R, OLIVEIRA, W. Especialização produtiva primária e meio ambiente em período recente na Amazônia. Novos Cadernos NAEA: v. 14, n. 2, p. 283-302, dez. 2011, ISSN 1516-6481.

Produto interno bruto dos municípios 2005-2009. (Contas nacionais, n. 36). Contas regionais do Brasil 2010. (Contas nacionais, n. 38). In: www2.dbd.pucrio.br/pergamum/...0410597_06_cap_01.pdf, Acesso: março de 2013. 